\title{
Disseminated lupus vulgaris: a case report
}

\author{
Burce Can, Ilkin Zindanci, Zafer Turkoglu, Mukaddes Kavala, Vasfiye Ulucay, \\ Filiz Topaloglu Demir \\ Department of Dermatology, Istanbul Medeniyet University, Goztepe Training and Research Hospital, Istanbul, Turkey
}

\begin{abstract}
Lupus vulgaris is a secondary form of cutaneous tuberculosis which persists for years if not treated. The head and neck are the most commonly affected sites. While less frequently arms and legs, and rarely the trunk and the scalp are involved. Herein, we describe a 73-year-old man with a 5-year history of slowly growing, atrophic, some eroded and ulcerated, red-brown plaques on his forehead, nose, cheeks, ear lobes, trunk and extremites. All of his disseminated lesions healed after antituberculosis therapy.
\end{abstract}

Key words: cutaneous tuberculosis, disseminated lupus vulgaris, lupus vulgaris

\begin{abstract}
A s a disease known for three thousand years, tuberculosis is most frequently seen in the developing countries. Cutaneous tuberculosis constitues less than $1 \%$ of all cases with tuberculosis. Cutaneous tuberculosis emerges in different clinical forms dependent on many factors notably pathogenicity of the microorganism, route of entry of the infection, immune state of the host, and antimicrobial resistance. In women lupus vulgaris or scrofuloderma, and in men tuberculosis cutis verrucosa, and ulcerative tuberculosis are more frequently seen forms. Characteristic lesion of the lupus vulgaris is a red-brown papule with a soft consistency termed as lupoma frequently localized on head and neck region $[1,2,3]$.

In this paper, a case with lupus vulgaris characterized by multiple atrophic and/or ulcerated plaques on the scalp, face, ears, anterior, and poste-
\end{abstract}

rior aspect of the trunk, upper, and lower extremities has been presented because of this rarely seen generalized form.

\section{CASE REPORT}

A 73-year-old male patient consulted to our outpatient clinics with complaints of ever-increasing number of non-healing wounds with foul-smelling discharge. Skin wounds of the patient were firstly appeared on his hip five years ago, and became more numerous since then. Biopsy material obtained one year ago was evaluated as chronic granulomatous dermatitis. His personal medical history was unremarkable, while his two siblings died of tuberculosis, and his son was still receiving tuberculostatic therapy. On his dermatological examination, red-violet atrophic plaque lesions with

Received: May 29, 2014 Revised: July 20, 2014 Accepted: July 25, 2014 Online: August 03, 2014

Correspondence: Filiz TOPALOGLU DEMIR. Medeniyet Universitesi Goztepe Egitim ve Arastirma Hastanesi, 


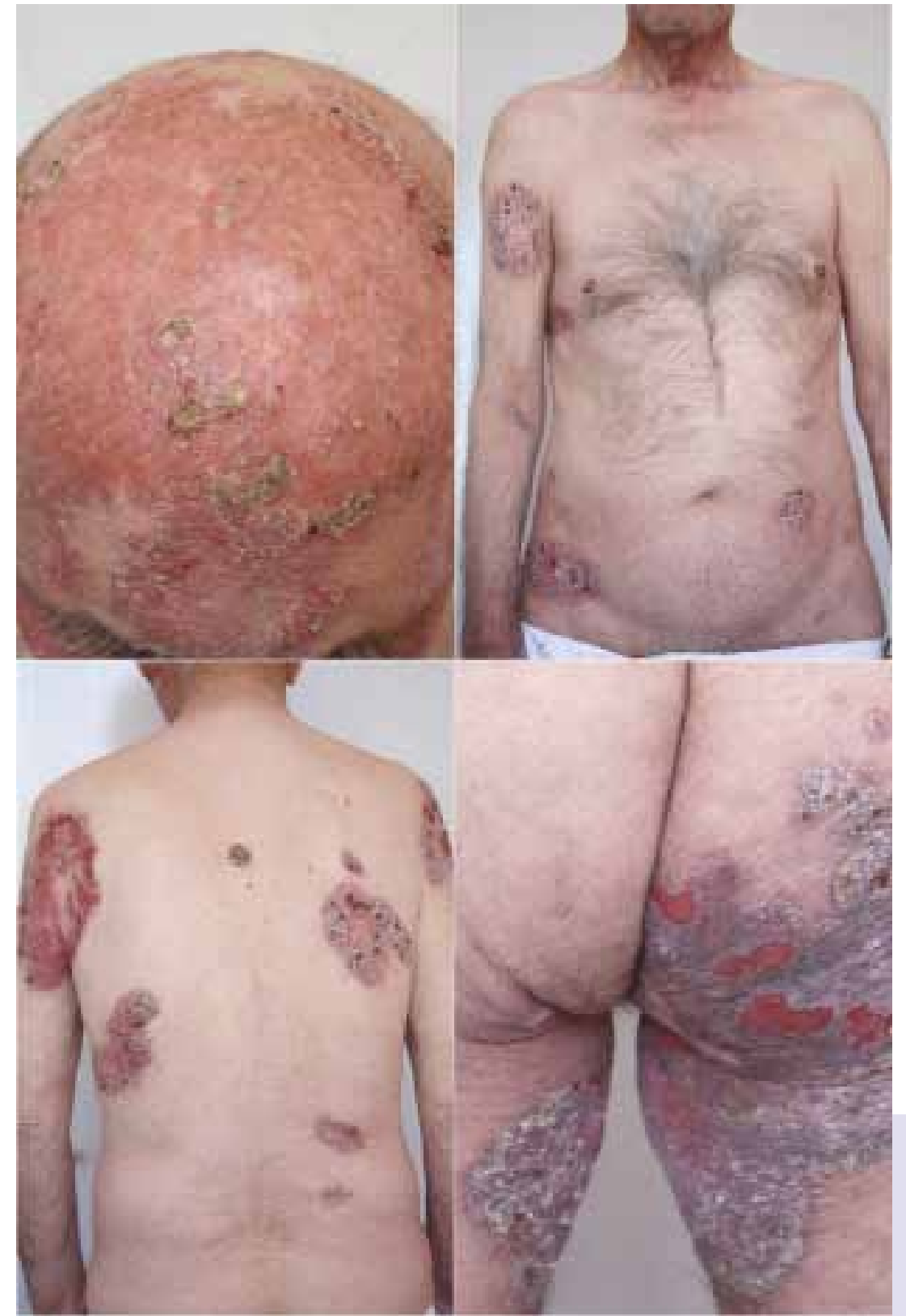

FIGURE 1. Atrophic plaque lesions with patchy areas of erosions and/or ulcerations localized on scalp, face, anterior, and posterior aspects of the trunk, extremities, and gluteal region. irregular contours, and patchy areas of adhered yellow-brown crusts, and squamas localized on the frontal, parietal, temporal, and malar regions, nose, and left ear were observed. Seventeen- 18 plaqueshaped lesions measuring $2-15 \mathrm{~cm}$ in diameter with adhered brown crusts, and squamas, and also eroded areas $0.5 \mathrm{~cm}-2.0 \mathrm{~cm}$ in diameter localized as islets on the anterior, and posterior aspect of the trunk, also on both upper, and lower extremities were seen. In addition to eroded areas on similarly appearing plaque lesions localized on the gluteal region, an ulcerated lesion $4 \mathrm{~cm}$ in diameter, and
$1-1.5 \mathrm{~cm}$ in depth striked our attention (Figure 1). Histopathological examination of the biopsy material revealed a large ulcerated area covered superficially with crusts, lymphocytic, and histiocytic infiltration, and giant cells within superficial, and middle layer of dermis, and granulomas more conspicuously on the periphery of the infiltrate (Figure 2).

Application of periodic acid-Shiff (PAS), and Erlich-Ziehl-Neelsen (EZN) staining couldn't detect any specific infectious agent. Laboratory anal- 
yses revealed anemia, hypoproteinemia, increased CRP, and sedimentation rate. With these clinical, and histopathological findings, the diagnosis of

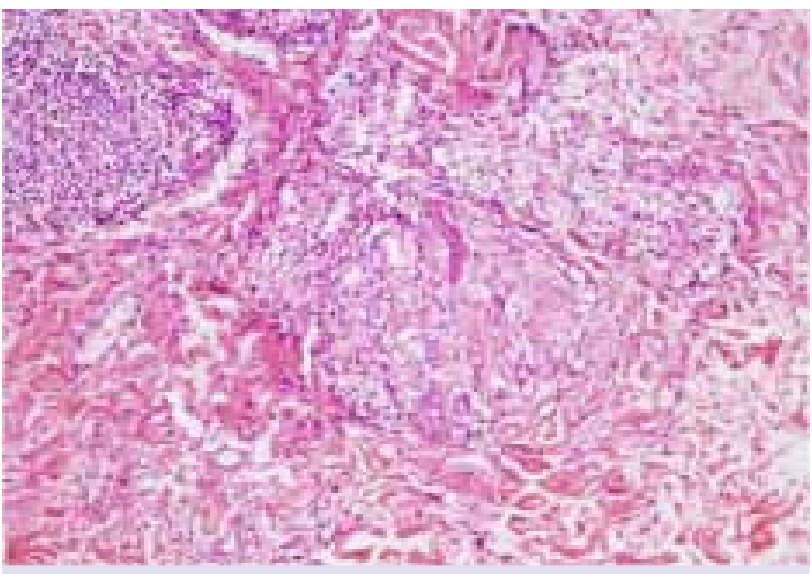

FIGURE 2. Giant cells, and lymphocytic, and histiocytic infiltration, and markedly conspicuous granulomas on the periphery of the infiltrate localized within the middermis (H\&E x 40).

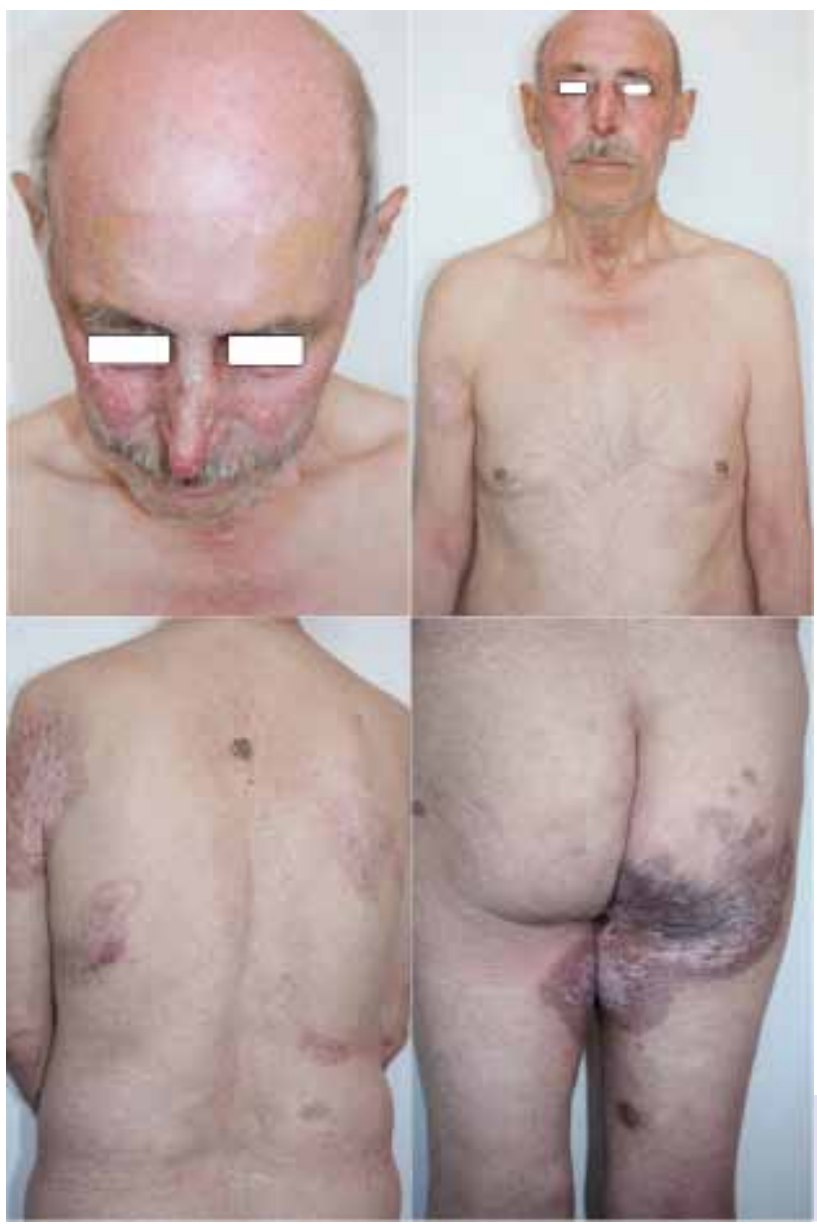

generalized lupus vulgaris was made. The patient with a $9 \mathrm{~mm}$-PPD reaction size, but without systemic involvement received antituberculostatic treatment with $300 \mathrm{mg}$ isonicotinic acid hydrazide, $600 \mathrm{mg}$ rifampicin, $1500 \mathrm{mg}$ ethambutol, and 3000 mg pyrazinamide for 2 months, then with $300 \mathrm{mg}$ isonicotinic acid hydrazide, and $600 \mathrm{mg}$ rifampicin for 4 months. At two months of the treatment, lesions regressed remarkably. At the end the sixth month all lesions healed with postinflammatory hyperpigmentation, hypopigmentation and/or atrophic scar (Figure 3).

\section{DISCUSSION}

Lupus vulgaris is a cutaneous tuberculosis seen in individuals who previously encountered tuberculosis bacilli, and those with moderate, and higher tuberculin sensitivity. It can become manifest via endogenous (hematogenous, lymphogenous) or direct spread from a focus of tuberculosis infection, while it can develop as an exogenous infection on verrucous tuberculosis, scrofuloderma scar, and BCC vaccination site. Characteristic lesions of lupus vulgaris are red-brown plaques spreading to the periphery leaving a scar tissue in the middle through the process of healing. These plaques are formed by accumulation of papullonodular lesions which look like apple jelly on diascopic examination. New lesions develop on atrophic areas. Secondary to ulcerations, cicatrices, and complications emerging during the progression of the disease, lupus vulgaris can manifest in diverse clinical forms; 1) plaque or planar form, 2) ulcerative or mutilant form, 3) vegetant form, 4) tumor-like form and 5) papulonodular form [2,3].

Although most frequently, head and neck region, and especially nose, cheeks, and earlobes are involved, less often, arms, and legs, and rarely trunk, and scalp can be affected. Oral, nasal, and conjunctival mucosa can be inflicted $[2,4,5]$. In our case, a widespread involvement all over the body including scalp (excl. mocosal surfaces) was observed.

Typical histopathological findings of tuberculosis, are tubercles consisting of epitheloid histio-

FIGURE 3. At the end of the sixth month regression of all lesions was observed. 
cytes, and Langhans-type giant cells surrounded by lymphocytes, and monocytes. In the center of these granulomas, caseification necrosis is observed. Bacilli are very rarely seen in lesions, and they couldn't be demonstrated in sections obtained. Mycobacterium tuberculosis can not be grown especially in cultures prepared from chronic lesions, and in patients with higher immunity $[2,3]$. Polymerase chain reaction (PCR) is another diagnostic method which can identify Mycobacterium tuberculosis -specific DNA particles in samples. Diagnostic sensitivity of PCR for skin lesions changes between 53 , and 77 percent $[6,7,8]$. Though for definitive diagnosis, identification of mycobacteria is required, it is not possible in most of the times. Diagnosis is usually made with clinicopathological correlation [3]. In our case, bacteria could not be identified in culture, and PCR analyses, and diagnosis was made based on clinical, and histopathological findings, and lesions healed with antituberculostatic drug therapy. Our case is extremely important in that in the diagnosis of skin tuberculosis necessity of consideration of not only PCR, and culture outcomes, but also history, clinical, and histopathological findings especially in cases with lesions which persisted for years has been demonstrated.

Treatment of skin tuberculosis shows similarities with other organ tuberculosis in many aspects. As is the case with our patient, following the treatment with isonicotinic acid hydrazide, rifampicin, ethambutol, and pyrazynamide lasting for 8 weeks, 16 weeks of treatment with isonicotinic acid hydrazide, and rifampicin is successful in most of the cases [2]. Since skin tuberculosis in undiagnosed cases, and inadequately treated patients leads a chronic course, within years it can result in severe tissue damage. Destruction of the nasal cartilage, ectropion, microstomy, keloid, lymphoedema, and functional disorders secondary to contractures are among sequelae that might become manifest years later in patients with lupus vulgaris. Besides, on the scars of lupus vulgaris prominently squamous cell carcinoma, basal cell carcinoma or even sarcoma can develop $[2,3]$.

In conclusion, when we encounter long-lasting disseminated atrophic and/or ulcerated plaque-like lesions localized on the trunk, and extremities, we should investigate our patients, and their intimates as for tuberculosis infection, and consider lupus vulgaris in differential diagnosis.

Informed Consent: Written informed consent was obtained from the patient who participated in this study.

Conflict of Interest: No conflict of interest was declared by the authors.

Financial Disclosure: The authors declared that this study has received no financial support.

\section{REFERENCES}

1. Tigoulet F, Fournier V, Caumes E. Clinical forms of the cutaneous tuberculosis. Bull Soc Pathol Exot 2003;96:362-7.

2. Yates VM, Rook GAW. Mycobacterial infections. In: Burns T, Breathnach S, Cox N, Griffiths C, editor. Rook's Textbook of Dermatology. 7th ed. Turin: Blackwell Science; 2004. p. 281-39.

3. Tappeiner G, Wolff K. Tuberculosis and other mycobacterial infections. In: Freedberg IM, Eisen AZ, Wollf K, Austen KF, Goldsmith LA, Katz S, editor. Fitzpatrick's Dermatology in General Medicine. 6th ed. New York: McGraw-Hill; 2003. p. 1933-49.

4. Sehgal VN. Cutaneous tuberculosis. Dermatol Clin 1994;12:645-53.

5. MacGgregor RR. Cutaneous tuberculosis. Clin Dermatol 1995;13:245-55. CrossRef

6. Hsiao P-F, Tzen C-Y, Chen H-C, Su H-Y. Polymerase chain reaction based detection of Mycobacterium tuberculosis in tissues showing granulomatous inflammation without demonstrable acid-fast bacilli. Int J Dermatol 2003;42:281-6. CrossRef

7. Degitz K, Steidl M, Neubert U, Plewig G, Volkenendt M. Detection of mycobacterial DNA in paraffin-embedded specimens of lupus vulgaris by polimerase chain reaction. Arch Dermatol Res 1993;285:168-70. CrossRef

8. Margall N, Baselga E, Coll P, Barnadas MA, de Moragas JM, Prats G. Detection of Mycobacterium tuberculosis complex DNA by the polymerase chain reaction for rapid diagnosis of cutaneous tuberculosis. Br J Dermatol 1996;135:231-6. CrossRef 